\title{
Regional Differences of China's Social Security Efficiency Based on DEA
}

\author{
Xiuzhi He ${ }^{1, \text { a }}$, Chaoqi $\mathrm{Li}^{2}$ \\ ${ }^{1}$ School of Government, Nanjing University, Nanjing, 210046, China \\ ${ }^{2}$ Guangzhou Resident Office, CNAO, Guangzhou, 510623, China \\ aabelnju@qq.com
}

Keywords: Social security; Input - output efficiency; Data Envelopment Analysis.

\begin{abstract}
Using the DEA model, this paper evaluated China's social security efficiency of 2013a, studying the financial investment degree and output of social security in every province. The study showed that the economic and financial input into social security in a majority of areas in our country is not adequate, that the use of social security fund was not reasonable. Finally, from facilitating economic development, increasing financial income, enhancing financial support for social security, making reasonable use of social security, this paper proposed the measures of increasing the input-output efficiency of social security in China.
\end{abstract}

\section{Introduction}

Social security is a basic system that ensures people's life and adjusts social allocation. The overall establishment of the social security system covering urban and rural residents as well as coordination and facilitation of the construction of urban and rural social security system is an important task in our country at present. With the economic and social development in China, financial input into social security is also increasing. However, due to various historical and objective reasons, total financial input into social security is still not adequate. Besides, there are remarkable provincial differences. Therefore, under the current situation, how to evaluate the input-output efficiency of social security and whether the financial input into social security gives into play effectively is always the focus that the academic circle and relevant practitioners are centering on. From the existing researches, it can be found that scholars mostly carry out studies from the perspectives of social security expenditure [1-4], performance of social security expenditure [5-6] and optimal scale of financial expenditure on social security [7-10], etc. However, there are still few researches on the input-output efficiency of social security. Moreover, in terms of methodologies, qualitative researches are in a large number with the focuses on theoretical exploration and little empirical analysis. Moreover, the evaluation on the input efficiency of social security is an important reference indicator when government conducts decision-making. On the basis, the paper selects the degree of economic and financial input into social security and whether the financial expenditure on social security expands the coverage of social security, applies the panel data in 30 provinces from 2006 to 2008, makes use of DEA method to evaluate the input-output efficiency of provincial social security in China, and analyzes relevant affecting factors.

\section{Methods and Data Sources}

DEA model. DEA (Data Envelopment Analysis) is a useful decision-making method with relative effectiveness that is adopted to evaluate similar departments or companies. The method is a systematic analysis method proposed by the famous American operational research experts, A. Charnes, W. Cooper and E. Rhodes based on the concept of "relative efficiency evaluation" in 1978[11]. Basic DEA model mainly includes $\mathrm{C}^{2} \mathrm{R}, \mathrm{BC}^{2}, \mathrm{FG}, \mathrm{ST}$ and so on. The model that is the most widely applied is $C^{2} R$ model that is effective relative to the scale and technology. The basic principle is: Suppose that there are $n$ decision-making units DMU $(1 \leq \mathrm{i} \leq \mathrm{n})$, every decision-making unit DMUi 
has $m$ input $x_{1 i}, x_{2 i}, \ldots, x_{m i}$ and $s$ output $y_{1 i}, y_{2 i}, \ldots, y_{s i}\left(x_{j i}, y_{j i}\right.$ are larger than 0$)$. Corresponding $v_{1}, v_{2}, \ldots, v_{m}$ and $u_{1}, u_{2}, \cdots, u_{s}$ are respectively the weight of $m$ input and $s$ output, noted down as:

$$
x_{i}=\left(x_{1 i}, x_{2 i}, \cdots, x_{m i}\right)^{T}, y_{i}=\left(y_{1 i}, y_{2 i}, \cdots, y_{m i}\right)^{T}, v=\left(v_{1}, v_{2}, \cdots, v_{m}\right)^{T}, u=\left(u_{1}, u_{2}, \cdots, u_{s}\right)^{T} \text {, we can get the }
$$
fractional programming of $\mathrm{C}^{2} \mathrm{R}$ :

$$
\left\{\begin{array}{l}
\max \frac{y_{i}^{T} u}{x_{i}^{T} v} \\
\frac{y_{i}^{T} u}{x_{i}^{T} v} \leq 1(1 \leq i \leq n) \\
v \geq 0 \\
u \geq 0
\end{array}\right.
$$

According to Charnes-Cooper transformation [12], Formula (1) can be transformed to:

$$
\left\{\begin{array}{l}
\max y_{i}^{T} u \\
y_{i}^{T} u \leq x_{i}^{T} v(1 \leq i \leq n) \\
x_{i}^{T} v=1 \\
v \geq 0, u \geq 0
\end{array}\right.
$$

We introduce non-Archimedean infinitesimal quantity $\varepsilon$ ( $\varepsilon$ is a very small positive number) to test the validity of DEA model. The dual programming of formula (2) can be obtained:

$$
\left\{\begin{array}{l}
\min \left(\theta-\varepsilon\left(e_{m}^{T} s^{-}+e_{s}^{T} s^{+}\right)\right) \\
\sum_{i=1}^{n} \lambda_{i} x_{i}+s^{-}=\theta x_{k} \\
\sum_{i=1}^{n} \lambda_{i} y_{i}-s^{+}=y_{k} \\
\theta, \quad \lambda_{i}, s^{-}, s^{+} \geq 0, \quad i, k=1, \cdots, n
\end{array}\right.
$$

Suppose the optimal solution to the linear planning (3) is $\lambda^{*}, s^{{ }^{*}-}, s^{{ }^{*}}$ and $\theta^{*}$, we can draw the following conclusions:

(1). When $\theta^{*}=1$, and $s^{{ }^{*}-}=0, s^{{ }^{+}}=0$, it is considered that DMU is effective in DEA. Under such a situation, the ith decision-making unit reaches the optimal state of "input-output". No adjustment is needed.

(2). When $\theta^{*}=1$, and $s^{{ }^{*}} \neq 0$ or $s^{{ }^{*}} \neq 0$, it is considered DMUi is effective in weak DEA. Under such a situation, the $i$ th decision-making unit can increase the output under the condition of maintaining the original input unchanged or maintain the output unchanged through reducing the original input. At this time, the economic activities are not optimal both in terms of technological efficiency and scale efficiency.

(3). When $\theta^{*} \neq 1$, and $0<\theta^{*}<1$, it is considered that $\mathrm{DMU}_{\mathrm{i}}$ is effective in non-DEA. It indicates that the ith decision-making unit has excessive input. It can be compressed according to a certain percentage.

(4). For decision-making units that are effective in non-DEA, we can improve the input or output through projection analysis so as to construct DEA effective decision-making units. Suppose that the input should reduce $\Delta x$ to maintain the output unchanged or that the output should increase by $\Delta y$ so as to maintain the input unchanged, then:

$$
\left\{\begin{array}{l}
\Delta x=\left(1-\theta^{*}\right) x_{j}+s^{*-} \\
\Delta y=s^{*+}
\end{array}\right.
$$

In addition, generally the optimal value of $\lambda_{i}$ in $C^{2} \mathrm{R}$ model can be used to judge the returns to scale. If there is a $\lambda_{i}^{*}(\mathrm{i}=1,2, \ldots, \mathrm{n})$ that realizes $\sum \lambda_{i}^{*}=1$, then DMU is unchanged returns to scale. If $\sum \lambda_{i}^{*}<1$, then DMU's return to scale increases. If $\sum \lambda_{i}^{*}>1$, DMU's return to scale decreases. 
Source of data and selection of variables. Because of the limitations of data obtainment, this study selects the data in 31 provinces of 2013a. The data are from Yearbook of China's Statistics and Yearbook of China's Labor Statistics in 2013a. The paper also adopts the cross section of 2013a to evaluate the input-output efficiency of overall social security. When evaluating the input-output in "economic and financial input - social security", we choose per capita GDPand total financial expenditure as the input variable because per capita GDP can reflect a region's economic status, while the total financial expenditure reflects a region's financial expenditure. In addition, financial expenditure on social security, percentage of financial expenditure on social security and per capita financial expenditure on social security are selected as output variables to investigate how much economic and financial expenditure is used into the construction of social security in each province.

\section{Results and Conclusions}

Results. Using DEA model, we get the result of provincial "economic and financial input - social security" input-output evaluation (Refer to Fig 1 for details, where DMUs from 1 to 31 represent Beijing, Tianjin, Hebei, Liaoning, Shanghai, Jiangsu, Zhejiang, Fujian, Shandong, Guangdong, Hainan, Jilin, Heilongjiang, Shanxi, Anhui, Jiangxi, Henan, Hubei, Hunan, Inner Mongolia, Guangxi, Chongqing, Sichuan, Guizhou, Yunnan, Tibet, Shaanxi, Gansu, Qinghai, Ningxia and Xinjiang in China.). The paper analyzes the result from three perspectives, i.e., pure technological efficiency, scale efficiency and common effectiveness of scale efficiency.

(1). Analysis of pure technological efficiency. Pure technological efficiency refers to the efficiency of utilization of economic development and financial expenditure on social security. If efficiency is "1", it means "effective", i.e., the utilization is reasonable. If efficiency is lower than "1", it means "invalid", i.e., the input is not fully utilized.

From Fig 1, it can be seen that among 31 provinces, the efficiency of utilization of economic and financial input into social security is valid in 8 provinces and cities, including Shanghai, Hainan, Heilongjiang, Gansu, NIngxia and so on. The efficiency of utilization of input is invalid in other provinces, especially Inner Mongolia and Fujian. After analysis, we find that middle and western areas make effective use of the economic and financial input into social security. The invalid regions are mainly in eastern areas. The current situation is commonly caused by the different economic development levels, unreasonable utilization of financial input into social security, etc.

(2). Analysis of scale efficiency. Scale efficiency mainly refers whether economic development level in each province and total financial expenditure on social security satisfy each region's demand on social security. If efficiency is "1", it means "effective", i.e., the region spends a large amount of economic and financial expenditure on social security. The region's demand on social security is satisfied. If efficiency is lower than "1", it means "invalid", i.e., the region spends a small amount of economic and financial expenditure on social security. The region's demand on social security cannot be satisfied.

From Fig 1, among 31 provinces, only the total amount of input into social security in Hainan, Heilongjiang, Qinghai, and Ningxia satisfies the local social security demand. However, the other 27 provinces' total input cannot satisfy the local social security demand. The situation in Tianjin, Guizhou and Jiangsu is particularly severe. From this, it can be known that the economic development level and the financial expenditure on social security are not inadequate. The region's social security demand cannot be satisfied. There is a need to continue enhancing the support for economic and financial expenditure on social security in each region.

The inadequacy of input is quite severe in Jiangsu, Tianjin, Zhejiang and Guangdong. However, despite sound economic development in these areas, they put a little amount of financial expenditure on social security. Qinghai and Ningxia are under-developed economically. However, their total financial and economic expenditure on social security can satisfy the local social security demand. It shows that economic development level is negatively correlated to the total amount of input into social security. 
(3). Analysis of common effectiveness of pure technological efficiency and scale efficiency. If a region's scale efficiency and pure technological efficiency are commonly valid, it indicates that the economic and financial expenditure on social security and fund utilization ratio in the region are both effective.

From Fig 1, we can see that among the 31 provinces of 2013a, only the pure technological efficiency and scale efficiency in Henan, Heilongjiang, Qinghai and Ningxia are commonly valid. However, although fund utilization ratio in Gansu, Tibet, Shanghai and Guizhou is effective, the scale efficiency is invalid, implying that the four regions should make reasonable use of the local economic development and financial input into social security.

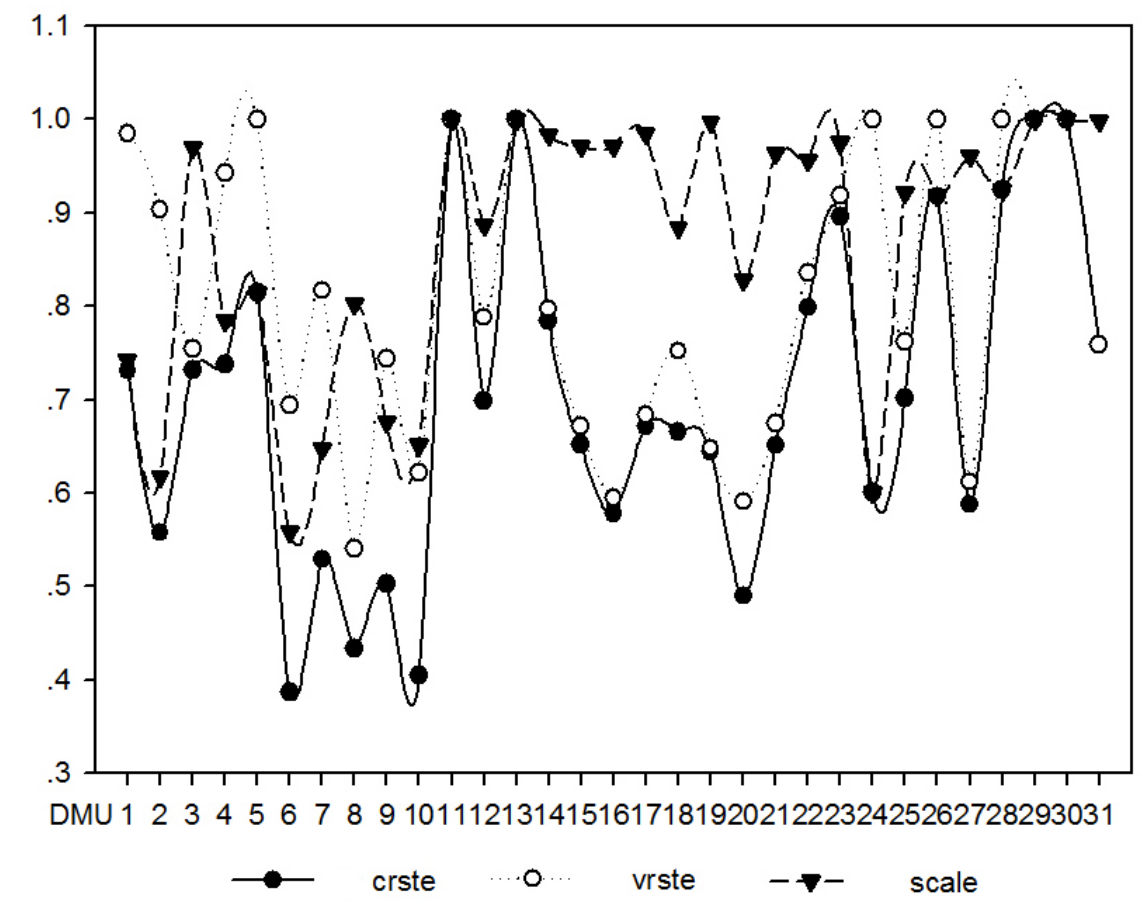

Fig 1."Economic and financial input - social security" input-output evaluation

\section{Conclusions.}

Based on the above results, we put forward that the domestic input-output efficiency of social security should be improved from the following perspectives.

Firstly, to accelerate the regional economic development and increase regional financial income is very important. The economic development level is an important guarantee of one country's and region's social security development. For the purpose of ensuring social security, economic development is of peculiar importance. As long as the economic development is sound, financial income can increase. The financial input into social security can possibly increase correspondingly.

Secondly, to continually enhance the financial input into social security. In general, the domestic social security is not adequate. Although some provinces develop quickly and the financial income increases year by year, the growth rate of financial expenditure on social security cannot keep pace with the increasing demand on social security. The financial expenditure on social security is still limited. A majority of provinces' financial expenditure on social security cannot satisfy the local social security demand. Therefore, the financial input into social security should still be consolidated.

Thirdly, to improve the utilization ratio of financial expenditure on social security. The study finds that the input into social security in many provinces is in a large amount. However, these provinces should make reasonable use of the financial input into social security. For this reason, it is also of great importance to set up a complete social security fund management and utilization system as well as make reasonable and effective use of the fund. 


\section{References}

[1] Shiyun Song,Chengling Li.China's social security expenditure level research from 1992 to 2006[J]. Chinese journal of population science. 2008(03) 38-46.

[2] Fengxi Pang,Pan Xiaozhen. Fiscal decentralization and local government spending on social security: based on the provincial panel data analysis [J]. Finance and economic. 2012(02) 29-35.

[3] Lu Ji Liu,Qiao Li, Xindan Zhang. Demographic changes and fiscal social security expenditure level research: based on the empirical analysis of provincial panel data [J].Journal of Guizhou University of finance and economics. 2014 (04) 91-97.

[4] Huibing Ke. China's spending on social security analysis of the regional differences [J].Journal of public management. 2009 (01): 55-63.

[5] Ping Zhang. To build our country social security expenditure performance evaluation index system [J].Chinese journal of social security. 2010 (07) 32-34.

[6] Ping Zhang. The difficulties and indicators of the performance appraisal of expenditure of our country social security system construction [J].Journal of Tianjin University of finance and economics. 2009 (06) 18-22.

[7] Xin Jiang. The optimal level of social security research in China [J].Soft science. 2012(05) 41-44.

[8] Zhenguo He.China's fiscal expenditure for supporting agriculture the optimal scale and its implementation [J].Chinese Rural Economy. 2006(08) 4-9.

[9] Shengli Yang,Zhenglong Li and Dongxin Lu.China's social security expenditure scale research [J].Reform and the strategic. 2010(09): 158-161.

[10]Zengwen Wang. The optimal scale of China's social security expenditure [J].Journal of Agricultural economics. 2010(01) 111-117.

[11] Charnes,A., Cooper W.W. And E.Rhodes. Measuring the Eficiency of Decision Making Units [J].European Journal of Operational Research. 1978(06) 29-444

[12] Charnes, A., Cooper, W. W. Programming with Linear Fractional Functionals [J]. Naval Research Logistics Quarterly. 1962(9): 181-196. 